\title{
Assessing the feasibility, acceptability and cost of introducing postabortion care in health centres and dispensaries in rural Tanzania
}

Monica Wanjiru

Population Council

Ian Askew

Population Council

Nzoya Munguti

Saumya RamaRao

Population Council

Rick Homan

See next page for additional authors

Follow this and additional works at: https://knowledgecommons.popcouncil.org/departments_sbsr-rh

Part of the Demography, Population, and Ecology Commons, International Public Health Commons, Maternal and Child Health Commons, Public Health Education and Promotion Commons, and the Women's Health Commons

How does access to this work benefit you? Let us know!

\section{Recommended Citation}

Wanjiru, Monica, Ian Askew, Nzoya Munguti, Saumya RamaRao, Rick Homan, Reheme Kahando, and John M. Pile. 2007. "Assessing the feasibility, acceptability and cost of introducing postabortion care in health centres and dispensaries in rural Tanzania," FRONTIERS Final Report. Washington, DC: Population Council. 


\section{Authors}

Monica Wanjiru, lan Askew, Nzoya Munguti, Saumya RamaRao, Rick Homan, Reheme Kahando, and John M. Pile 


\title{
Assessing the feasibility, acceptability and cost of introducing Postabortion Care in health centres and dispensaries in rural Tanzania
}

Final Report

July 2007

\author{
FRONTIERS Program \\ Monica Wanjiru \\ Ian Askew \\ Nzoya Munguti \\ Saumya RamaRao \\ Rick Homan
}

ACQUIRE Project

Rehema Kahando

John M. Pile

This study was funded by the United States Agency for International Development (USAID) through the EngenderHealth ACQUIRE Project and the Population Council's FRONTIERS in Reproductive Health Program, under the terms of Cooperative Agreement HRN-A-00-98-00012-00 and In-house Project 8019 53100. The opinions expressed herein are those of the authors and do not necessarily reflect the views of USAID. 


\section{Summary}

The EngenderHealth ACQUIRE Project has been supporting the Tanzanian Ministry of Health $(\mathrm{MOH})$ since early 2005 to decentralise the management of Post Abortion Care (PAC) services to Primary Health Care facilities (health centres and dispensaries), with the intention of bringing services closer to women who are unable to access them at district hospitals. The decentralised service has been pilot tested in one district, Geita District in Mwanza Province, northern Tanzania, to provide the Ministry with experience and operational information before it expands decentralization to the rest of the country.

The pilot project was introduced by ACQUIRE in eleven health facilities (seven health centres and four dispensaries) in May 2005. In November 2005, the Population Council FRONTIERS Program began documenting the process of decentralising PAC and prospectively assessing its feasibility, effectiveness and cost. FRONTIERS collected data in selected pilot sites at two points in time; November 2005, the findings from which were provided to the MOH and ACQUIRE to address issues arising from introduction of the intervention; and in September 2006, to assess the feasibility, cost and effectiveness of the intervention. The specific objectives of this evaluation were to:

- Document the process of introducing and implementing the package in health centres;

- Assess changes in provider knowledge, attitudes and practices in the management of miscarriage and abortion complications that can be attributed to the training;

- Describe experiences of postabortion clients and their perceptions of the new service;

- Document changes in community attitudes and knowledge about abortion complications following introduction of the services, and the acceptability of local facilities offering PAC services;

- Examine the kinds of referral networks put in place by the intervention, and document their effectiveness and,

- Establish the additional resources that would be required by the $\mathrm{MOH}$ to support introduction of PAC services.

Data were collected from a sample of one hospital and five health centres during the first round of data collection; no dispensaries were then offering PAC. During the second round, two dispensaries were included and a sixth health centre. A combination of data collection methods was used: in-depth interviews with service providers and with PAC clients; facility audits; and focus-group discussions with members of the communities served. Service records were reviewed to determine PAC and other RH service utilization trends. Financial records were reviewed to establish government expenditures on medical supplies, program support costs and staff emoluments.

Overall, the results indicate that PAC services are feasible and easy to set up in the lower health facilities, and are considered to have offered a satisfactory level of quality of care for clients. The intervention is seen to have broadened service providers' range of clinical skills and led to an increase in the number of women accessing family planning services after the evacuation. Facilities are well prepared to provide the PAC service, and few clients are being referred for advanced clinical management for incomplete abortions within 12 weeks of conception. 
However, linking MVA clients with other RH services besides FP remains weak in most of the sites; few facilities have managed to integrate STI/HIV screening and services into the PAC service. The costs of introducing and sustaining the service were calculated and projections provided to inform the $\mathrm{MOH}$ and its development partners of the anticipated costs of extending PAC to all district hospitals and health centres in Tanzania.

In conclusion, this project has demonstrated that decentralizing PAC services to health centres and dispensaries is feasible and effective, and the approach could be scaled up at a reasonable cost to other lower level facilities in Tanzania. 


\section{Acknowledgements}

The authors would like to acknowledge the support received from different individuals and institutions during designing and implementing the study as well finalizing this report. We are grateful to the ACQUIRE Project and FRONTIERS Program for providing material and financial support without which this study could not have been possible. Special mention must be made of Dr Moshi Ntabaye and Leah Manongi, formerly of ACQUIRE, and Nzoya Munguti, formerly of FRONTIERS, who were all involved in getting this study started, and in the first round of data collection.

Support for this assessment was provided by the USAID PAC Working Group. We would also like to thank Carolyn Curtis, USAID/W for her technical input.

We would also like to express our deep appreciation for the tremendous support received from the Geita District Health Management Team and staff in charge of the health facilities visited in the pilot sites. We are especially grateful for the support provided by the District Reproductive and Child Health Coordinator during the fieldwork and the research assistants for their devotion during data collection.

Finally, we would like to thank all the individuals in Geita District, who agreed to participate in this study.

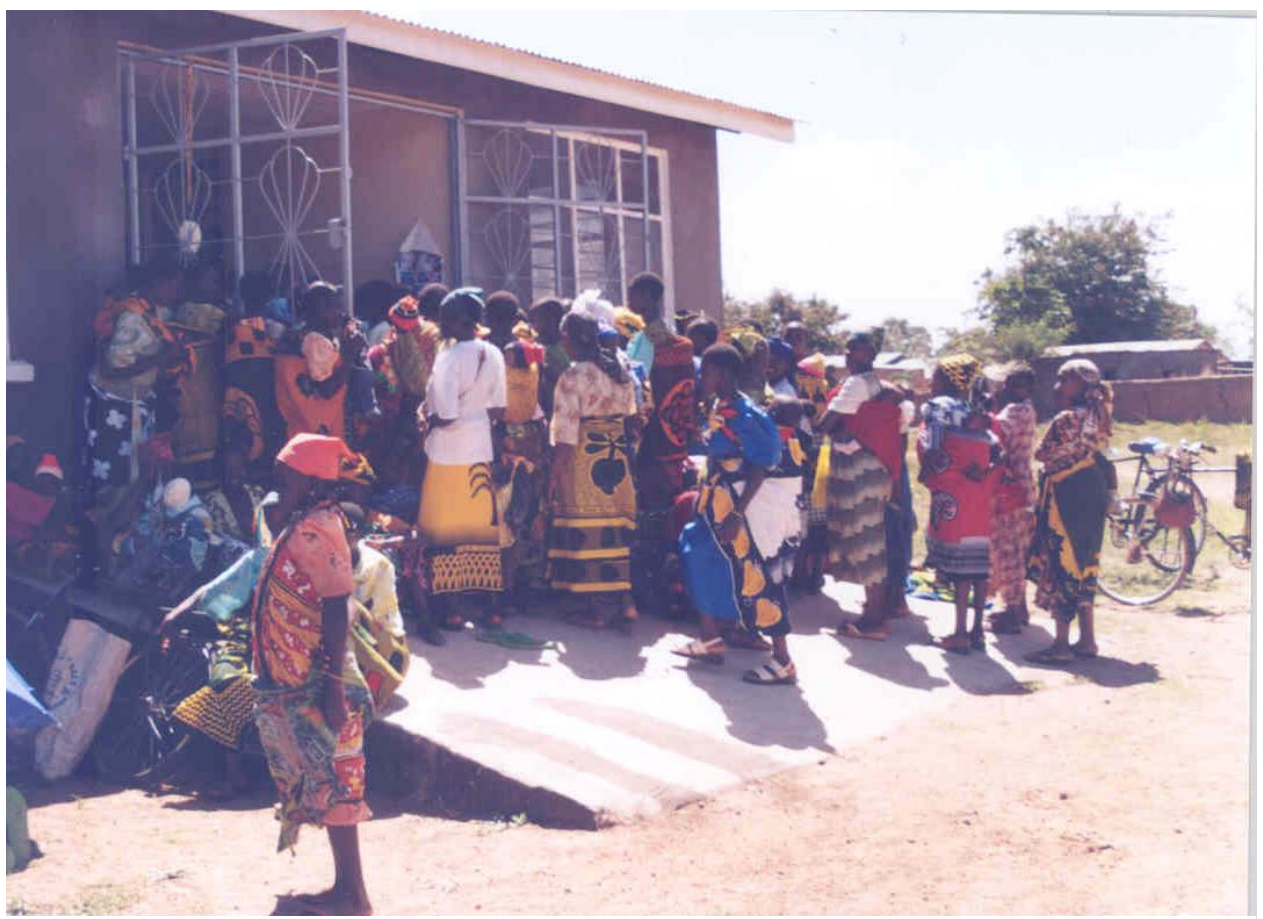

Clients wait for services at Bukoli Health Centre, Geita District 


\section{Table of Contents}

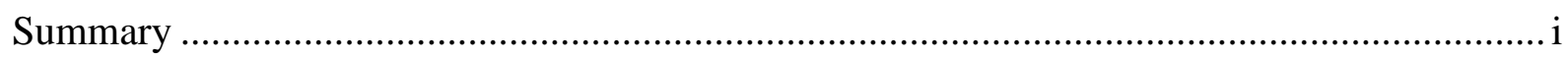

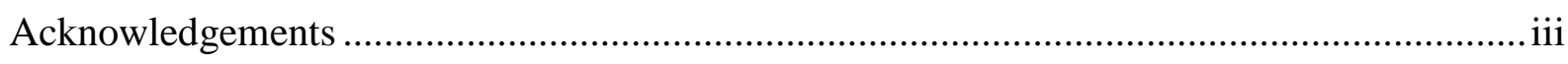

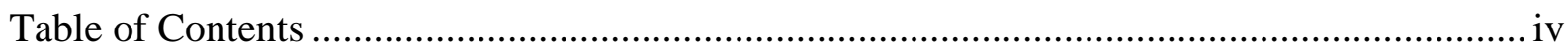

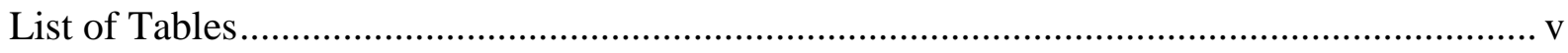

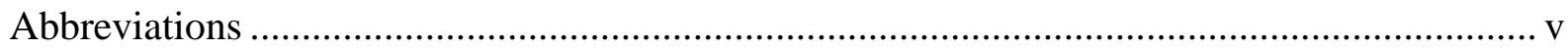

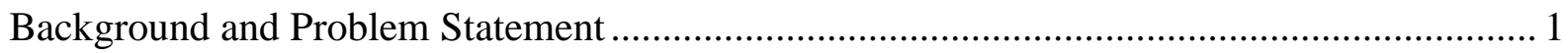

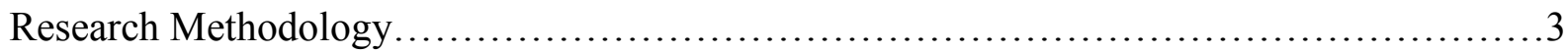

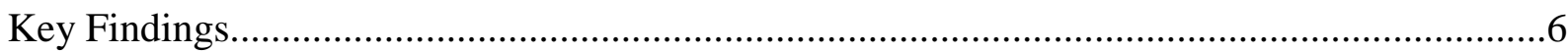

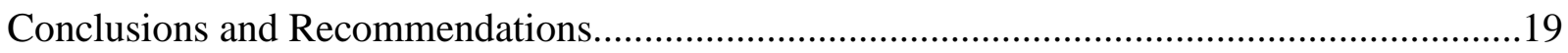

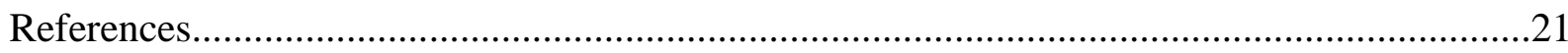

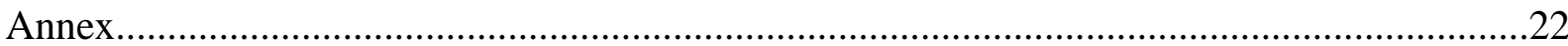




\section{List of Tables}

Table 1: Summary of numbers of clients up to September 2006 ..................................... 12

Table 2: Number of clients receiving FP counselling and service .................................... 13

Table 3: Value of resources to implement and provide PAC services......................16

Table 4: Estimated additional cost of expanding the program by type of facility.............17

\section{Abbreviations}

PAC Postabortion Care

CHMTs Council Health Management Teams

FP Family Planning

MOH Ministry of Health

MTUHA Mfumo wa Taarifa za Uendeshaji wa Huduma za Afya

MVA Manual Vacuum Aspiration

PAC Post Abortion Care

PAFP Post Abortion Family Planning

OJT On the-Job-Training

VCT Voluntary Counselling and Testing 


\section{Background and Problem Statement}

Tanzania is in the process of decentralising the management of its health services to the district level, in a bid to improve the delivery of essential health services, including reproductive health, in the country. District Health Management Teams (DHMTs) are expected to take charge of all planning, budgeting and management of their district health program. In the decentralised setting, DHMTs run the local health services, using local revenues and allocations from the central government, and according to the national health policies, which are set by the Ministry of Health.

EngenderHealth, through the ACQUIRE Project and with financial support from USAID, is providing technical assistance to the ministry to implement the National Package of Essential Reproductive and Child Health Interventions ${ }^{1}$ within the decentralised system. This package includes Post Abortion Care $(\mathrm{PAC})^{2}$ as an essential service, alongside other reproductive and child health services, emergency obstetric and postpartum care, family planning, and the prevention and management of childhood illnesses. The national guidelines identify PAC as one of the elements that can be provided at lower level health facilities, through delegating Manual Vacuum Aspiration (MVA) to nurses and midwives, and making the service available at health centre level. Besides increasing physical access to a safe and effective evacuation procedure, decentralised PAC services would link more women to family planning and other reproductive health services, thereby reducing their risk of another pregnancy and increasing access to STI/HIV services. As part of its technical assistance to the MOH, the ACQUIRE

\begin{abstract}
Structure of health services in Tanzania:
1. Village Health Post Services:

This is the lowest level of health care delivery in the country, providing community-based preventive services. Usually each village health post has two village health workers chosen by the village government from amongst the villagers, and given a short training before they start providing services.
\end{abstract}

2. Dispensary Services:

This is the second stage of health services. The dispensary caters for 6,000 to 10,000 people and supervises all the village health posts in its ward. It is often headed by a nurse and offers basic primary health care.

3. Health Centre Services:

A health centre is expected to cater to a population of about 50,000 people, which is approximately the population of one administrative division. Health centers offer general outpatient services, laboratory services, and $\mathrm{MCH}$ services, including deliveries, and are headed by clinical officers.

4. District Hospitals:

Each district is supposed to have a district hospital. It supervises all health centers in the district, and offers most specialized medical services, including theatre services.

5. Regional Hospitals:

Regional Hospitals offer similar services like those agreed at district level; however, regional hospitals have specialists in various fields and offer additional services which are not provided at district hospitals.

\footnotetext{
$1 \quad$ Ministry of Health. National Package of Essential Reproductive and Child Health Interventions in Tanzania. Ministry of Health, Tanzania, (1999)

2 Postabortion care encompasses the three core components of PAC developed by USAID. It includes Community and service provider partnerships for prevention (of unwanted pregnancies and unsafe abortion), mobilization of resources (to help women receive appropriate and timely care for complications from abortion), and ensuring that health services reflect and meet community expectations and needs; Counselling to identify and respond to women's emotional and physical health needs and other concerns; Treatment of incomplete and unsafe abortion and complications that are potentially life-threatening; Contraceptive and family planning services to help women prevent an unwanted pregnancy or practice birth spacing; and Reproductive and other health services that are preferably provided on-site or via referrals to other accessible facilities in providers' networks.
} 
Project began a pilot project in 2005 to test the decentralisation of PAC services to a selection of health centres and dispensaries in Geita District, Mwanza Region.

The dispensary is the lowest health service facility in Tanzania, offering basic services, and most often with a staff of one, a nurse (see box on page 1). Dispensaries refer cases they cannot handle to the health centre, which in turn refers to the district hospital.

Experience to date in Tanzania has been limited to providing PAC services in district hospitals, and little is known about the feasibility of offering these services at lower level facilities. The experience of EngenderHealth in Senegal ${ }^{3}$ shows that, while it is possible to decentralise PAC services to such facilities, more research is needed to understand how to improve referral systems, and on how to improve and maintain quality in the services, especially in the rural areas. The Senegalese project found that the following problems persisted after decentralising the services:

- Lack of sustained, comprehensive and systematic counselling - for instance, some clients left unaware of the risk of pregnancy. In addition, in some sites, failure to protect client confidentiality during counselling was observed, even after training staff and providing the physical infrastructure;

- Delayed access to services, due to shortage of trained staff, and to stock-outs of essential commodities;

- Infection prevention practices were found to be inconsistent and not good enough, especially instrument processing and waste management;

- Barriers persisted denying clients access to services, especially the cost of treatment, which though reduced, was still too high for most clients.

\section{Description of the Intervention}

In early 2005, ACQUIRE and the MOH began the pilot intervention in Geita District, which comprised three elements: training of service providers; setting up PAC services and infrastructure; and community outreach. Geita District was selected because it has some of the highest numbers in the country of women seeking services for miscarriage and abortionrelated complications, estimated at about 400 per month by the district hospital.

ACQUIRE began the pilot project by carrying out a rapid facility assessment of 15 facilities in the district to establish their preparedness to provide PAC services, guided by the USAID PAC Strategy (see box). The assessment included

\section{Core Components of Postabortion Care}

USAID has developed the following as the three core elements of its postabortion care model:

- Emergency treatment for complications of induced or spontaneous abortion

- Family planning counselling, service provision, STI evaluation and treatment, HIV counselling and/or referral for testing

- Community empowerment through awareness and mobilization

This model closely reflects the key elements promoted by the global PAC Consortium --- USAID PAC Strateav. 2004

EngenderHealth. 2003. "Taking postabortion care services where they are needed: An operations research project testing PAC expansion in rural Senegal," FRONTIERS Final Report. Washington, DC: Population Council. 
staffing levels and skills, clinic infrastructure, availability of basic equipment and supplies required for PAC, infection prevention protocols, and privacy of the space for postabortion treatment and counselling. In Tanzania, treatment of incomplete abortion using sharp curettage (D\&C) is included in the medical training curriculum for doctors, but not of other cadres of health staff (clinical officers, nurses and midwives). Eleven facilities were selected for inclusion in the pilot - seven health centres, three dispensaries and the district hospital.

Fifteen service providers from the eleven facilities underwent a two-week training in PAC, which included clinical management of incomplete abortion using MVA, screening and management of sexually transmitted infections, client counselling on STIs and HIV, family planning, infection prevention and community education. The trainees practised MVA procedures at Geita and Sengerema district hospitals (Sengerema was included because Geita did not have adequate numbers of clients for all the trainees). These providers were expected to pass on these skills to others at their facility through on-the-job-training. ${ }^{4}$

Each trainee was provided with the first MVA set, including speculum, cannulae and syringes, and job aids. ACQUIRE facilitated the procurement of MVA kits through the MOH. Each MVA set has a life of approximately 150 procedures, after which it has to be replaced. Each provider was also given a set of infection prevention charts, which were to be put up in the MVA room to remind them of the process. Providers were also asked to open a new register exclusively for MVA clients. These registers were improvised from hard-cover note books. The providers were expected to implement the full range of services within the PAC package, including client counselling, screening and treatment/management for other reproductive health needs, before discharge and after evacuation using MVA or D\&C.

In addition, health facilities offering PAC services were expected to undertake outreach activities to sensitize the surrounding communities on the problems of abortion-related complications, and the need for a rapid action when such complications emerge. Each trainee developed a facility work plan, detailing how they were going to implement the PAC services in their facilities after the training.

\section{Research Methodology}

\section{Research Questions}

The Population Council's FRONTIERS Program was requested by USAID/Washington to work with ACQUIRE in documenting the process of decentralising PAC services in the pilot project sites, and to establish the feasibility, acceptability and cost of introducing PAC services at lower level facilities in Tanzania. Specifically, the study sought to answer the following questions:

\footnotetext{
${ }^{4} 7.5$ hours of the Tanzania PAC curriculum are devoted to organizing PAC/RH Services of which 30 minutes of didactic time is dedicated to conducting on-the-job training for other PAC/RH providers. The curriculum has tools for assessing trainees clinical and theoretical competence (pre- and post-tests, checklists), but does not evaluate provider's skills to train others.
} 
- Is it feasible to introduce a PAC service into lower level facilities in Tanzania?

- How has the introduction of PAC in the lower level facilities changed the way existing resources are utilised?

- Does the Tanzania health system have the capacity and resources to support introduction of PAC at lower level facilities?

- What effect does training staff in PAC have on their knowledge, attitude and practices regarding abortion and its management, and on the quality of care?

- What experiences and perceptions do clients have of the new PAC services, especially their quality?

- What are the community attitudes and knowledge about abortion complications, and their perceptions of local facilities offering PAC services?

- What kinds of referral networks are required in Tanzania for the decentralised service to be effective?

- What is the cost, to the government and to clients, of providing the PAC service at lower level facilities?

In the pilot project, the health facilities were expected to treat incomplete abortions using MVA, to provide FP and STI screening and treatment, and to make referrals for HIV testing, counseling and management from the lower facilities to the district hospital and to other sites offering the service. The assessment sought to measure the following key variables.

- Feasibility: The number and types of challenges faced when introducing PAC services at lower level facilities; the extent to which services provided needed to be re-organised; the proportion of service providers able to provide PAC services, and the degree to which activities to introduce the new service were implemented as planned.

- Effect of introducing PAC services: Compared with the situation pre-intervention, the number of women who accessed the service after its introduction; and proportion of women undergoing treatment for an incomplete abortion receiving counselling and services for other reproductive health needs as compared to pre-intervention.

- Knowledge, attitudes and practices of the service providers in managing abortion complications: The proportion of trained service providers who have correct knowledge of managing abortion complications; the proportion that can demonstrate competence in undertaking the complete PAC package; and the proportion of trained providers expressing attitudes supportive to PAC clients.

- PAC client experiences: clients expressing positive or negative views about and satisfaction with the PAC services received.

- Community knowledge and attitudes: Representative community members' notions about abortion, its complications, and the acceptability of a local health facility offering treatment for incomplete abortions.

- Effectiveness of referral networks: the kinds of referral networks in place, the numbers of clients being referred up from lower level health facilities and across the different sites, and the perceived efficiency of the system. 
- Cost of introducing the PAC package: The financial cost of setting up the new service, including the cost of training staff, restructuring the physical infrastructure, and ensuring availability of medical supplies and equipment. Where possible, the cost to the client of accessing and receiving the service are calculated.

\section{Data Collection}

Data to measure the key variables were collected in two phases: first, in November 2005, which included the costing analysis, to gain an understanding of the service functioning shortly after the intervention had been introduced so that findings could be fed back quickly to the MOH and ACQUIRE to allow any necessary adjustments to be made. The second phase was conducted in September 2006, which would enable an assessment of the extent to which the original intervention could be sustained over time, and also to allow assessment of trends in service utilization to be undertaken. Data were collected from a sample of nine facilities - six health centres, the district hospital, and two dispensaries (see box). The sample was purposively

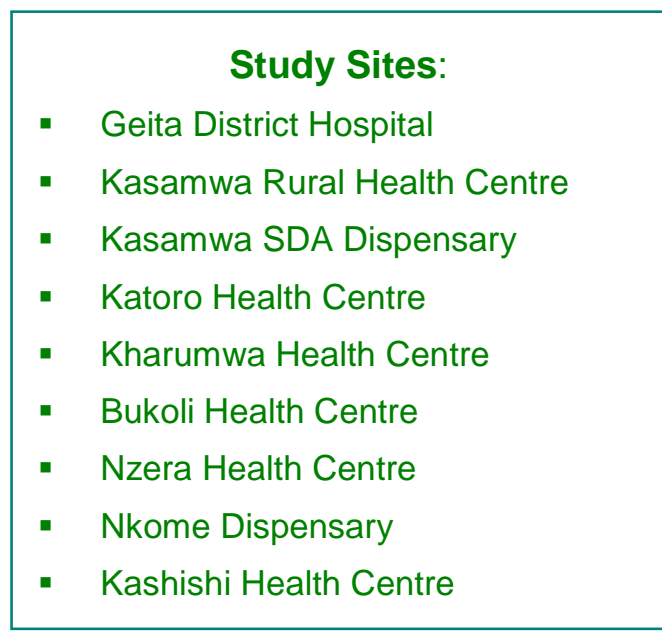
chosen in consultation with ACQUIRE and MOH officials.

The following data collection methods were used; all the tools were developed jointly by FRONTIERS and ACQUIRE staff involved in the assessment.

- In-depth interviews with service providers using a semi-structured questionnaire, to assess the intervention's feasibility and effect, including infrastructure, provider knowledge, attitudes and practices. In total, 12 providers were interviewed.

- In-depth interviews with PAC clients, using a semi-structured questionnaire to assess their own experiences of the service within the facility. In total, 20 clients were interviewed.

- Focus-group discussions with members of the communities served by the study facilities to establish their perceptions on abortion, its complications, and the acceptability of PAC services at the local health facility. In total, eight FGDs were conducted, four for men, and four for women.

- Review of facility records: service registers were reviewed at 7 sites (the district hospital and 6 health centres) to determine trends in the numbers of clients seeking PAC service since its introduction in May 2005, and the services provided.

- Cost Analysis: information on resource use during the introduction of the intervention in the selected sites was collected for implementation and service delivery phases including supervision. Costs incurred during the planning phase were not examined in this assessment, as they are context specific and therefore not generalizable.

All interview tools were developed in English, and then translated into Kiswahili so that the interviews could be conducted in Kiswahili; the transcripts were translated back into English for 
analysis. Although great care was taken to retain the original dialogue as accurately as possible, there is the possibility that some meaning may have been distorted or lost in the translation.

\section{Key Findings}

The following section highlights the key findings of this assessment, organised around the study's key questions.

\section{Feasibility of introducing PAC service into lower level facilities}

To establish whether it is feasible to introduce PAC services into the lower level health facilities in Tanzania, this study considered the following factors:

i) Number and type of new equipment or facilities required by the pilot sites to set up and sustain the PAC service

ii) Extent to which existing services have been re-organised to allow for new services

iii) Number of service providers able to provide the new services

iv) Types of challenges faced and how these are addressed

v) The degree to which the PAC service has been implemented as originally planned.

From the data collected, introduction of PAC services into health centres and dispensaries appears to have been fairly straightforward, requiring very little change in the existing infrastructure or reorganisation of services and procedures. None of the providers interviewed reported having encountered problems significant enough to either delay or hamper the introduction of the service. In none of the facilities was any new space needed to accommodate the PAC service; all facilities identified an existing room and did minor renovations to allow MVA to be provided. Three facilities did not have an exclusive MVA room; in Kasamwa and Katoro health centres, the MVA services were provided in the delivery room, and in Kharumwa, at the mini-theatre. At Nkome Dispensary, the MVA room is also sometimes used for VCT services.

During the first round of data collection, it was established that the facilities already had the equipment required to start MVA services, including beds with stirrups and chairs. Every facility was provided with at least one MVA starter kit (MVA set including speculum, cannulae, and syringes). Some facilities bought limited amounts of extra supplies, ranging from plastic buckets, heavy duty gloves, to bleach. Only Geita District Hospital reported buying towels, sheets, mackintosh (protective rubber sheets), and powder soap.

Concerns emerged during the second round of data collection that there were shortages of some essential supplies at the pilot sites, specifically recurrent expendables and sterilization consumables. Nine of the eleven providers interviewed said that their facilities had recorded increases in the use of basic medical supplies and some drugs since introduction of PAC. While some did not see this as a problem, others were concerned about what they considered a slow response to their requests for new supplies by the district hospital. 
"Yes, we have experienced problems with getting supplies, there are problems with procurements and we sometimes have to wait for long." (Provider, Nzera HC).

Another added:

"we haven't had diclofenac since we started (the PAC service). I have ordered from the stores, but there is none, and so I have to borrow from other health centres. It is terrible to do an MVA without giving the client pain relief." (Provider, Kashishi $\mathrm{HC}$ )

Other providers expressed concern that there did not seem to be any plans with the district health management for replacing MVA kits or supplying extra sets. Providers in some of the busier facilities felt that the kits provided were nearing time for replacement, and the Ministry had not indicated how they would get new sets. It was also mentioned that having only one kit sometimes led to delays in attending to clients if the kit was undergoing sterilisation. This concern was also expressed by staff at the district hospital.

"One challenge (we face) is that we have only two sets of the MVA kit, and we have used them since we started. They are over-used, we need new kits”. (Provider, Geita District Hospital)

Although discussions with some of the district RH supervisors indicated that MVA kits were already included in the medical supplies provided by the regional Medical Supplies Department (MSD), the health staff interviewed did not seem to be aware that they could include these kits in the orders for essential supplies.

\section{Number of service providers able to provide the PAC service}

There has been little turnover of the staff trained in PAC in the pilot sites, and several more have been trained through on-the-job training. At the time of the second phase of data collection, except for two facilities, every facility visited had at least two members of nursing or clinical staff who could provide the service. Of the eleven providers interviewed, three had received onthe-job training (OJT). It must be noted that the PAC training briefly covered the concept of OJT and did not include practice in OJT skills; in addition, trainees were not given manuals or guides to assist them in on-the-job training.

Most providers complained that they did not have enough staff at their facilities that could do MVA. This was the most commonly cited challenge facing the pilot sites, especially the busier ones like Bukoli and Nzera health centers. This concern had also been expressed during the first phase, but providers indicated that they would be undertaking on-the-job training to address this problem. However, it appears that staff who had undergone on-the-job training did not feel confident to conduct the procedure on their own:

"The other staff I have here are medical assistants and they are afraid of doing the MVA procedure if I'm not with them, "' (provider, Bukoli).

\section{Introduction of the PAC model}

During the first phase of data collection, it was found that the pilot sites had not fully implemented the PAC model as intended by ACQUIRE. FP counselling and services were consistently good in that a majority of clients were counselled and left with a contraceptive. However, the pilot sites had not managed to link MVA treatment with STI screening and 
management, or to include VCT information in the post-procedure counselling. In the second phase of the assessment, however, there had been a marked improvement in efforts to integrate STI services. Nearly all the providers interviewed said that they counselled clients on STIs, besides providing FP information and services. Syndromic management and blood testing for syphilis were specifically mentioned in several sites as well as partner treatment.

"Some clients come here with obvious STDs, so we treat those straight away. Sometimes, we have to screen them by asking questions, then we can use RPR or VDRL if we think the client is sick," (provider, Kashishi HC)

However, problems remained in most sites with integrating VCT information and services into the PAC service. Only two sites (Geita District Hospital and Nkome Dispensary) have VCT services on-site; other facilities have to refer clients to the nearest site. But interviews with the providers revealed that referrals for VCT are not happening very often. Although all providers interviewed said that they give clients information on HIV, referrals were rarely made for testing, with the most frequently cited reason being that clients would not make the journey to the district hospital for testing:

"If the client agrees, we advise her to go for the test, but they are reluctant because it is far, they say if it (the testing) was here they could have done it, but the hospital is far" (provider, Nzera HC).

At Nkome Dispensary, out of the 64 MVA clients treated since the PAC service started, only 10 received counseling and testing services. In Geita District Hospital, referrals for VCT, which is available at the same hospital, are not systematic or consistent and depend on the attending provider and the perceived interest of the client. Clients receive some counselling after the MVA treatment, and are then sent to the VCT centre for testing "if they show interest" as reported by one provider. There did not appear to be any specific efforts made to ensure that clients get systematic counseling and referral.

During the first phase of data collection, it was found that the existing MVA registers could not describe any linking of MVA clients with STI/HIV services because the PAC registers had no column to show referrals for VCT and other RH issues and no information on STI management (treatment and/or referrals). It was recommended that the MOH and ACQUIRE address this issue, and during the second phase the records were amended in five of the facilities (Nkome, Kashishi, Katoro, Bukoli, and Nzera) to have additional columns indicating STI diagnosis and tests, including the outcome. Except for Nkome Dispensary, none of the registers show any information related to HIV counselling and service.

\section{Community education and mobilization}

The pilot sites had been expected to implement community outreach and mobilization activities to sensitize the local communities about abortion, and the need for a fast response in cases of complications. This assessment found that there have been very few community activities implemented by the pilot sites. The providers include information on abortion including miscarriage during health talks given to ANC clients and some providers reported giving talks during village meetings. This shortcoming was attributed to the shortage of staff available to do outreach work, which is understandable in the pilot sites where there are only one or two PAC providers with other routine duties. 


\section{Effect of introducing PAC services}

The effect of introducing PAC services into lower level facilities was measured in terms of several outcomes: knowledge of the service providers; perceived effect on workload; client experiences with the service; community knowledge and attitudes; and the numbers of women using the services.

Provider knowledge about managing abortion complications: Providers at the pilot sites were found to have good levels of knowledge about preparing the client for the procedure, management of the MVA procedure, handling complications, and general management of the service, including infection prevention. All 11 providers interviewed could explain, without prompting, the key steps in handling a client from the first interview through to post-procedure counselling. They could readily explain the most common post-procedure complications a woman treated with MVA could suffer - all mentioned infection, fever, abdominal pain and continued bleeding. They also had correct knowledge of the conditions that require emergency referral, with the most commonly cited reasons being when the pregnancy was longer than 12 weeks, severe bleeding, and if the client was anaemic.

"If we get a client with sepsis, for instance if she had the abortion at home and it did not fully come out, she can come with very severe infection, which can be difficult to treat especially if she has other problems like anaemia. Such a client we refer to Bugando (the regional hospital)" (provider, Geita District Hospital)

The providers interviewed were quite consistent in observing the correct infection prevention procedures when handling MVA kits and disposing of waste. The most common procedure for cleaning the MVA instruments was soaking in chlorine, rinsing in soapy water, boiling, and airdrying, and for disposing of biological waste was burning in an incinerator; two sites said that they bury the waste.

Providers also showed good knowledge about postabortion family planning, with all saying that they would give a method to the client before discharging her, unless she has serious health reasons. Several also said that, besides counselling the woman on the risk she was taking if she refused to take a method, they would include the husband in the counselling. When asked how they would handle a client who was reluctant to take up a method after MVA, some responses were that:

"If she is married, I will tell her to go and come with her husband so we can discuss it (family planning) further" (provider, Geita District Hospital)

"I will tell her that since she has refused a method, to at least use condoms or abstain to avoid getting pregnant. I would also teach her how to use the calendar or traditional method" (provider, Kharuma HC)

Adding PAC services to workload: During the first round, providers said that they did not feel their workload had increased much with the new service. During the second assessment, however, five of the eleven providers reported that the new service had added significantly to their workload: 
"Yes, there is more work now because the one doing PAC is still expected to rotate to other ward duties in the hospital" (provider, Geita DH)

"Yes, it has affected the services because sometimes it causes delays in serving other patients since I'm the only one here" (provider, Katoro HC)

"After starting this service, it has made my work difficult ... there are few providers here so I have to do everything. Sometimes I wake up at night to come and attend to clients and I often work beyond the normal hours" (provider, Bukoli HC).

Asked what they would like to see done to improve the service further, nearly all providers mentioned training more staff to provide the service. All agreed that they had gained new professional skills through PAC, which had improved the quality of care they were able to give to their clients.

Client experiences with the PAC service: Clients presenting with bleeding in pregnancy reported being attended to with minimal delay. Of the 20 clients interviewed in nine facilities, 16 said that the waiting time was quite short, mostly less than half an hour. It appears that providers and their facilities have made efforts to create awareness so that clients arriving with bleeding in pregnancy are promptly attended to:

"I did not wait for long, maybe like five minutes only, then he called me inside and started examining me" (client, Kashishi $\mathrm{HC}$ ).

However, several clients said that the providers did not explain to them what the problem was after examination, or even tell them what the treatment would involve. Twelve of the twenty clients said no explanations were given about their condition before treatment commenced:

"He didn't tell me anything, I only explained what the problem was, then he treated me and I left. He did not tell me anything," (client, Geita DH)

In both assessments, none of the clients reported having been mistreated by the staff during the MVA procedure. Clients described the manner in which they were treated by staff during their time at the clinic as kind, good, and respectful:

"They treated me kindly with respect. No one was allowed to come into the room where I was being treated, it was locked and there was only me and the two doctors" (client, Geita $\mathrm{DH})$.

Five of the twenty clients felt that there was inadequate privacy during the examination and the MVA procedure. Ten clients reported experiencing significant pain during the MVA procedure, even though all said that they had been given pain medication. In all the pilot facilities, clients are routinely given pain medication, mostly diclofenac tablets or injection. However, only four of the clients had been told about health problems likely to occur after the MVA procedure, contradicting reports by the providers that they routinely counselled clients on immediate complications.

Only four clients reported not being given any information on family planning during their stay at the health facility. Most clients mentioned being told about pills, injectable and implants; none mentioned condoms or the IUD. Client FP counselling did not routinely include information on possible side effects; 11 of the 16 clients given FP counseling were not told about side effects. 
Most (12) also felt that they did not get enough information about contraception. Six clients said had not received any family planning method before discharge.

Only seven clients reported having received any information on sexually transmitted infections. Of these, four had also received treatment for an STI. Only three of the 20 clients reported being told about HIV, and advised to go for a test; however, none were given a referral letter for the VCT service.

"Yes they told me to go (for test), but I didn't think they were serious. They didn't give me any letter, so I don't know whether I'll go," (client, Kasamwa HC)

Community knowledge and attitudes: As noted above, community outreach was intended to be an integral component of the intervention, but very few activities actually took place.

Consequently, these comments probably do not reflect the effect of any actions within the project, but are their perceptions about postabortion services generally. In the FGDs and interviews with local leaders, participants acknowledged that abortion and miscarriage were a problem in their community. There was a high level of awareness of the most common signs of a pregnancy in danger of miscarrying:

"Abortion" is a problem here in the village, but our women are shy and try to hide, sometimes they don't say they have a problem until it is too late... sometimes they hide, they don't want to say the pregnancy has aborted until they fall sick," (participant, FGD Men, Katoro HC).

Although respondents were happy that the local health facilities were able to treat mothers suffering abortion complications, most were quite critical of the way some of them handled the women. It was felt that some staff were not sympathetic, that they kept the women waiting too long before treating them, and that staff did not educate pregnant mothers on danger signs and what to do in emergencies:

"Most of the staff use rude and harsh language on pregnant women and people from rural areas are never given any information" (participant, FGD Men, Geita DH).

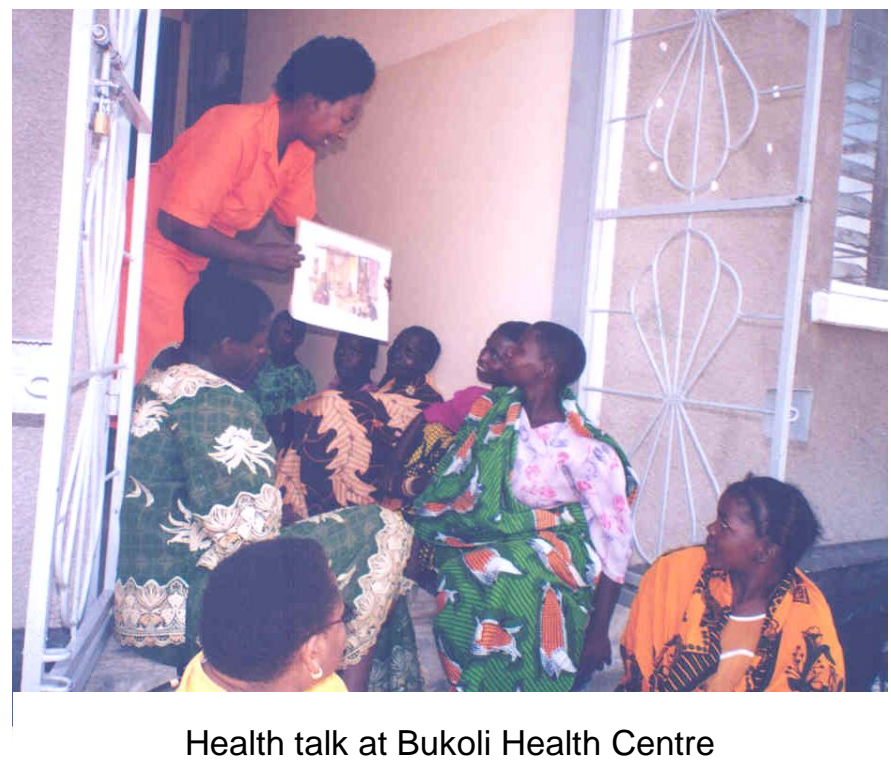

Respondents said they would like to see the health facilities provide more public health education and information to pregnant mothers and their partners so that they could act quickly in case of a threatening abortion:

5 The interviews were conducted in Kiswahili and used the same phrase, 'mimba kuharibika' for abortion and miscarriage. 
"It would be good if we could have meetings to educate local people so they can understand what to do when there is a problem. Some of the problems we have are because people do not know what to do," (participant, FGD Men, Katoro HC).

Participants were asked if there were reasons that would cause a woman suffering a miscarriage or abortion to avoid visiting the local public health facility for assistance. Several reasons were given, the most commonly cited being lack of reliable transportation, bad experiences at the facility, and fear of the nursing staff:

"Sometimes she can decide to just stay at home and rest rather than go to be mistreated by the nurses... she thinks, if I go they'll just give me a bed, I can just stay at home and not go to be abused" (participant, FGD Women, Geita DH).

"Sometimes you have to carry the patient on the bicycle for a long distance and it is very painful for her. It is very bad especially at night or when it is raining” (participant, FGD Men, Katoro HC).

FGD participants expressed support for FP services for women after a loss of pregnancy, to delay the next pregnancy, and to allow the mother to recover. However, it was felt that if the woman was childless, she should try to conceive as soon as she was well again, and not take too long.

"She has to talk to her husband so they can agree whether to wait, because he might not want her to use family planning. To avoid family quarrels, it is better to ask the husband first especially if she does not have a baby" (participant, FGD Men, Kasamwa HC).

Number of clients using PAC services: Prior to the intervention, only two of the facilities offered any PAC services - Geita District Hospital and Kharumwa Health Centre (which also functions as a sub-District Hospital), and they have continued to provide PAC, now using MVA. All facilities at which the PAC service was newly introduced have started serving clients, at rates of 0.8 to 5.6 women per month on average (see Table 1), with a mean monthly rate over the 17 month period for these seven facilities of 23 clients.

Table 1: Numbers of clients up to September 2006 (17 months post-intervention)

\begin{tabular}{|c|c|c|c|c|}
\hline \multirow{2}{*}{ Facility } & \multicolumn{2}{|c|}{ MVA clients after 7 months } & \multicolumn{2}{c|}{ MVA clients after 17 months } \\
\cline { 2 - 5 } & Total & Monthly mean & Total & Monthly mean \\
\hline Geita District Hosp & 245 & 35.0 & 374 & 22.0 \\
\hline Kharumwa HC & 139 & 19.9 & 206 & 12.1 \\
\hline Kashishi HC & 37 & 5.3 & 66 & 3.9 \\
\hline Bukoli HC & 35 & 5.0 & 79 & 4.5 \\
\hline Nkome Disp & 32 & 4.6 & 64 & 3.8 \\
\hline Nzera HC & 39 & 5.6 & 55 & 3.2 \\
\hline Kasamwa HC & 25 & 3.6 & 49 & 2.9 \\
\hline Kasamwa SDA Disp & 9 & 1.3 & 14 & 0.8 \\
\hline Katoro HC & 32 & 4.6 & 65 & 3.8 \\
\hline Total & 593 & 84.7 & 972 & 57.2 \\
\hline
\end{tabular}

All figures obtained from the $M V A$ registers on site 
There appears to have been a slight decrease in the number of women attending for PAC services across all of the facilities since the service was introduced; the monthly average was 84.7 during the first seven months and has decreased to 57.2 for the full 17 months ${ }^{6}$. We believe that declines in Geita District Hospital occurred because clients sought services at health centres instead. It is important to continue to track utilization over a longer time frame to assess if there is a stabilizing of caseloads.

Across all facilities, there were very few referrals for further clinical management of incomplete abortions, which may suggest that the facilities are now prepared to handle the cases coming to them. The few cases at the health centres were for pregnancies above 12 weeks, or for surgical contraception.

Number of women receiving post abortion family planning: Data from the MVA registers (see Table 2) indicate that counseling on postabortion family planning was almost universal in all clinics except one. Moreover, most clients left the facility with a method, although this varied widely across clinics. Kharumwa Health Centre, the Kasamwa SDA Dispensary, and Geita District Hospital had the highest proportions of clients leaving without a method. Why this is the case in Geita DH is not clear; in the other two facilities, FP counselling and methods are not provided at the same place where the MVA procedure is done, and the client is sent to the FP clinic at the MCH Unit, and this could lead to some clients dropping out of the referral process.

Table 2: Proportion of clients receiving FP counselling and methods

\begin{tabular}{|l|c|c|c|}
\hline \multicolumn{1}{|c|}{ Facility } & $\begin{array}{c}\text { Total MVA } \\
\text { clients } \\
\text { May '05 - Sep'06 }\end{array}$ & $\begin{array}{c}\text { \% received FP } \\
\text { counselling }\end{array}$ & $\begin{array}{c}\text { \% all clients } \\
\text { received FP } \\
\text { method }\end{array}$ \\
\hline Geita DH & 374 & 96 & 57 \\
\hline Nzera HC & 55 & 91 & 89 \\
\hline Bukoli HC & 79 & 99 & 90 \\
\hline Kharumwa & 206 & 98 & 54 \\
\hline Kasamwa HC & 49 & 100 & 90 \\
\hline Kasamwa SDA Disp & 14 & 14 & 14 \\
\hline Nkome Disp & 64 & 100 & 72 \\
\hline Katoro HC & 65 & 94 & 58 \\
\hline Kashishi HC & 66 & 100 & 97 \\
\hline
\end{tabular}

6 Numbers at the Kasamwa SDA Dispensary have remained low, probably because the facility is private and charges for the MVA service, and because for most of the time there have been no trained staff on site. 
Other reproductive health services: Linking MVA clients with STI and HIV services was a component of the original PAC model, but during the first round assessment, none of the facilities were doing this. After this was noted, five facilities started to offer STI screening, but only one, Bukoli Health Centre, has kept systematic records. These indicate that every one of its 44 MVA clients seen since the first assessment was screened for STIs (although how they were then managed is not recorded). No facility has indicated any HIV activities for the MVA clients. For STI services, this may be because providers do not record these services on the MVA register but maintain separate STI registers. The two facilities with VCT services (Geita DH and Nkome Dispensary) also maintain separate VCT registers where all VCT-related data are recorded. An expanded MVA register should include space for recording STI and VCT services.

\section{Effectiveness of referral networks put in place by the intervention}

Effectiveness of the referral network was determined by the types of referral mechanisms existing, and the numbers of clients being referred across different levels of facilities. Service providers were asked questions on the numbers of clients that had been referred from their institutions, for what type of care, how the patient transfer is organised, and how feedback is given / received from the other facility.

Documentation suggests that there are very few referrals being made from the health centres and dispensaries to the district hospital. The numbers of clients referred for complications of incomplete abortions or to access other RH services are negligible. Since the ACQUIRE project started, 14 referrals were recorded for either a serious infection, a pregnancy over 12 weeks, or client requests for surgical contraception. This low number of referrals may reflect the preparedness of the lower level facilities to deal with problems as they emerge. Interviews with health centre and district hospital staff indicate, however, that some referrals from dispensaries to health centres are not documented, so that it is difficult to know exactly how many are being made or how effective the system is. In addition, it appears that clients being referred sometimes do not get a referral letter, and that follow-up of the client is rarely is made by the referring facility:

"Staff in dispensaries do not usually write referral letters, they just tell the women to come here, so I never know who has been referred from where” (provider, Nzera HC).

"Me, I have never seen a client come with a referral letter, although me I give them one if they have to go to Geita" (provider, Kharumwa HC).

\section{Cost of resources in the pilot project}

To establish the additional costs that would be required by the $\mathrm{MOH}$ to introduce PAC in these facilities, quantitative data were gathered for the period November 2004 - October 2005 on resource use during the introduction of the intervention through training and start up, and during service delivery, including supervision. Resources used during the planning phase were not included as they are context specific and therefore not generalisable. The assessment employed a 
simple systems analysis model ${ }^{7}$ that relates inputs (resources used to provide services) with outputs (services produced) to estimate the incremental cost of introducing the intervention package. Costs were estimated using a three-step process as follows ${ }^{8}$ :

$\checkmark$ Identification of all activities and resources required to introduce the package;

$\checkmark$ Measuring resources in their "natural units" (e.g. labour is measured in hours);

$\checkmark$ Converting these natural units into cost estimates by multiplying the quantity of each resource used by an appropriate unit cost.

Activities costed in the training and start up phase included: training of service providers, purchase of educational materials, capital investments such as equipment, and refurbishing space for manual vacuum aspiration (MVA) services. Activities costed during the service delivery and supervision phase included: performance of MVA procedures, prescription of drugs, use of nonpharmaceutical supplies, provision of FP commodities to the PAC clients, and supervisory visits.

The first part of the analysis documents the resources used during the pilot project by the ACQUIRE Project and by the Ministry of Health. Expenditure records from EngenderHealth were used to establish the resources ACQUIRE provided, and to establish the resources used by the Ministry of Health, key informant interviews and a review of the Geita district health budget, 2004, was used. Annex 1 summarizes data requirements for this assessment, study methods/techniques used, and data sources. The second part of the analysis estimates the incremental costs that would be required by the $\mathrm{MOH}$ to introduce PAC services in a new site, at district hospital and health centre level, assuming that all resources would be financed by the ministry. The adjustments to the results from the pilot project include:

- Reductions in the cost of trainings to reflect use of existing $\mathrm{MOH}$ training mechanisms. In the pilot project, the ACQUIRE Project used external consultants to carry out the training. In this estimate, while separate trainings would still be required, the trainers (ToTs) would be from the Ministry and therefore costs are much lower.

- Removal of the cost of supervision to reflect incorporation within the existing supervisory activities. In the pilot project, the ACQUIRE Project team made additional supervisory visits with the reproductive health district coordinator and incurred additional costs for transport and per diems.

- The MVA kits and space refurbishment would impose additional equipment costs on the ministry budget, the rest of the equipment such as examination tables, delivery beds, and chairs would represent re-alignment of existing resources

- The cost of program support, direct labour time for service providers and space for MVA services were assumed to be met through a redeployment or shifting of resources rather than through additional budget expenditures.

- With respect to supplies, no adjustment is made since these represent the cost of additional supplies used to provide PAC services. The implicit assumption is that the PAC clients

7 Janowitz B. \& Bratt J.1994. Methods for Costing Family Planning Services, New York: United Nations Population Fund.

8 Drummond MF, O’Brien B, Stoddart GL, and Torrance GW. 1997. “Cost Analysis," in Methods for the Economic Evaluation of Health Care Programmes, 2nd Edition, Oxford: Oxford University Press, pp. $52-95$ 
represent clients that otherwise would not be using these supplies and therefore additional supplies will be required to support these services.

A per facility incremental cost (average for facilities) was computed by dividing total incremental costs by number of facilities surveyed. These estimates could be used by the Ministry to budget for PAC services by simply multiplying the cost per facility by expected number of facilities to be covered in expanding the PAC service. In both analyses, costs were classified into two main categories:

- Up-front Costs: these are the additional resources required to set up the PAC service, prior to being able to deliver the services. These include equipment purchases, infrastructure improvements, and the training of providers

- Recurrent Costs: these are the additional resources required to provide the services and include: supervision (pilot project only), medical supplies such as drugs, FP commodities and non-pharmaceutical products.

Overall, up-front costs accounted for $71 \%$ of the total program costs in the first year while recurrent costs accounted for $29 \%$. This distinction allows for an estimate of the incremental resources required in the initial year at each new facility, as well as in subsequent years.

During the pilot project, the ACQUIRE Project supplied $80 \%$ of the costs (mainly up-front costs such as training and equipment) and the Ministry of Health $20 \%$. Table 3 shows the magnitude of costs and sources of funding for the implementation and provision of PAC services for one year. The ministry contribution was in the form of capital improvements, such as equipment and space for MVA, drugs, FP commodities, labour time and other supplies.

Table 3: Value of resources for providing PAC services, by funding source

\begin{tabular}{|c|c|c|c|c|}
\hline Resource inputs & ACQUIRE & МOH & TOTAL & Proportion (\%) \\
\hline \multicolumn{5}{|l|}{ Up-Front Costs: } \\
\hline Equipment $^{1}$ & 933 & 1,846 & 2,779 & $18 \%$ \\
\hline Training $^{1}$ & 8,196 & & 8,196 & $53 \%$ \\
\hline Sub-total Up-Front Costs & 9,129 & 1,846 & 10,975 & $71 \%$ \\
\hline \multicolumn{5}{|l|}{ Recurrent Costs: } \\
\hline FP commodities ${ }^{2}$ & & 567 & 567 & $4 \%$ \\
\hline Drugs & & 202 & 202 & $1 \%$ \\
\hline Other supplies ${ }^{3}$ & & 477 & 477 & $3 \%$ \\
\hline Supervision $^{4}$ & 3,336 & & 3,336 & $21 \%$ \\
\hline Sub-total Recurrent Costs & 3,336 & 1,246 & 4,582 & $29 \%$ \\
\hline Total Costs & 12,465 & 3,092 & 15,557 & $100 \%$ \\
\hline Percent (\%) & $80 \%$ & $20 \%$ & $100 \%$ & \\
\hline
\end{tabular}

Exchange rate used 1 US\$ = 1,089 TZ Shs. (Central Bank of Tanzania annual average for 2004).

$1=$ Expenditures were incurred upfront and therefore not annualized

$2=$ Includes pills, condoms (male and female), injectables, Norplant insertions and IUDs

$3=$ Includes consumables such as syringes, needles, cotton, gloves, detergents and kerosene

$4=$ Conducted by the ACQUIRE team and the RH district coordinator for Geita. 


\section{Resources required by MOH to expand PAC to new sites}

To estimate the cost of scaling-up the PAC program to other $\mathrm{MOH}$ facilities, the training and supervision costs supported through the ACQUIRE were adjusted to reflect their incorporation within the existing training and supervision structures of the $\mathrm{MOH}$. Using existing $\mathrm{MOH}$ Trainers of Trainers (TOTs) at national or regional level was estimated to reduce training costs by about $35 \%$, due to savings in per-diems, travel and accommodation incurred by external facilitators. Similarly, incorporating monitoring and supervision activities into existing district level supervision eliminates the need for additional supervision resources. No additional expenditures for service providers or program support are anticipated during program expansion.

Table 4: Estimated Additional Cost of Expanding the Program by Type of Facility

\begin{tabular}{|c|c|c|c|c|}
\hline \multirow{2}{*}{ Resource Inputs } & \multicolumn{2}{|c|}{ Cost Per Hospital $^{1}$} & \multicolumn{2}{|c|}{ Cost per Health Centre ${ }^{2}$} \\
\hline & (US\$) & $(\%)$ & (US\$) & $(\%)$ \\
\hline Up-Front Costs: & & & & \\
\hline . Equipment & 350 & $16 \%$ & 146 & $20 \%$ \\
\hline Training & 1,076 & $50 \%$ & 448 & $62 \%$ \\
\hline Sub-total Up-Front Costs & 1,426 & $67 \%$ & 594 & $82 \%$ \\
\hline Recurrent Costs: & & & & \\
\hline . Additional FP commodities & 315 & $15 \%$ & 63 & $9 \%$ \\
\hline Additional Drugs & 99 & $5 \%$ & 26 & $4 \%$ \\
\hline Additional Other supplies & 303 & $14 \%$ & 43 & $6 \%$ \\
\hline . Supervision ${ }^{3}$ & & & & \\
\hline Sub-total Recurrent Costs & 717 & $33 \%$ & 132 & $18 \%$ \\
\hline Overall Additional Costs ${ }^{4}$ & 2,143 & $100 \%$ & 726 & $100 \%$ \\
\hline
\end{tabular}

$1=$ For one district hospital (Geita)

2 = Data has been pooled and averaged for 4 health centres (Nzera, Bukoli, Khalumwa and Kashishi)

3 = Additional supervision costs estimated to be zero since this activity could be

Incorporated into existing supervisory structures

$4=$ Exchange rate used 1US\$ = 1,089 TZ shs (Central Bank of Tanzania), annual average for 2004

As shown in Table 5, during the first year of expanding the program to other facilities, the Ministry would be required to spend an additional US $\$ 2,143$ at each district hospital and about US\$726 per health centre. Currently the MOH owns and operates 89 hospitals and 296 health centres countrywide. A full expansion to cover all of these would cost the ministry US $\$ 405,623$ $($ Hospitals $=\$ 190,727$, Health Centres $=\$ 214,896)$ during the first year of project expansion. Most of the additional expenditures would be up-front costs, (67-82\% depending upon type of facility) for procuring MVA equipment and training service providers. Note, upfront costs are higher for the hospital level because more MVA kits are provided and more providers are being trained per facility at the hospital level. Recurrent expenditures would account for 18-33\% of the total additional costs per facility for purchasing additional FP commodities, drugs and other supplies used by the PAC clients. The percentage share for recurrent costs is lower in the health centres due to the lower volume of cases expected. 


\section{Costs to clients}

Clients were asked how much they had spent to obtain the PAC service. The most spontaneous response was "I never spent any money", but on probing, it emerged that clients do indeed spend some money to obtain the service. Three of the five clients interviewed said they had spent money, mostly to purchase drugs and for transport: "In total I spent one thousand five hundred (1500) on all the services I was given," (client, Kasamwa HC). Probed about purchasing medication, one client said, "They were the only items I paid for", and another, "I cannot remember how much I spent on drugs. Though I never bought any drugs from outside the centre". No clients reported having paid any consultation fees. Whatever cost clients incur appears to be negligible and likely not to be a deterrent to accessing the PAC service. This is confirmed by findings from the FGDs: "The doctors agree to treat the woman who has had a miscarriage without any payment. After being treated that is when the brother or family will look for money because of the treatment that was given to the woman, " (Participant, male FGD, Kasamwa HC). 


\section{Conclusions and recommendations}

The findings of the first assessment indicated that the PAC pilot project was feasible, effective and acceptable to both the local communities and the services provides. It also concluded that the project was potentially affordable and sustainable, if the Tanzania MOH could include continued financing of the investments required to keep the service going. The second assessment confirmed the viability of this program; a key recommendation is that the pilot decentralisation program should be scaled up to other regions in Tanzania because it has benefits at the community level.

However, the assessment also revealed some key weaknesses in the implementation that the $\mathrm{MOH}$, with appropriate support from ACQUIRE or others would need to address as they expand to new areas:

- Sustained access to essential procurements: Some providers had experienced difficulties in getting recurrent supplies of essential commodities, including expendables and pain control medication. Concern was expressed about replacing MVA kits, some of which were already worn out. Although MVA kits are in the list of essential drugs and equipment, and are available in the MOH system through the MSD, providers did not seem aware that they could order the kits along with other essentials. The DHMTs need to include their procurement in the annual plans so that facilities can receive new kits when due.

- Continued capacity building: To fully integrate PAC into lower level facilities, the MOH needs to ensure that there are adequate staff with the requisite skills and competency to provide the service. Nearly all providers complained about lack of sufficient trained staff. While on-job-training to pass on skills is one training mechanism, it needs to be strengthened because providers reported a lack of confidence in their training abilities. Further, the $\mathrm{MOH}$ should reconsider the feasibility of providers posted at health centres and dispensaries to conduct OJTs given the low caseloads at these levels. A sustainable and viable approach would be to strengthen the skills of supervisors to support PAC services and encourage them and the trainees to function as preceptors after preceptor training.

- Record keeping: There is a lack of consistency in the information captured in the pilot facilities' MVA registers, making it difficult to identify the range of services provided. The first assessment had recommended that the MOH and ACQUIRE address this issue, but changes have been made in only a few of the facilities. The MOH should consider providing facilities with a standardised PAC register, in which providers can record all the necessary information regarding client management. This would also serve as a job aide to remind providers of all the services they should be giving the client after MVA treatment. In the long term, the $\mathrm{MOH}$ should incorporate all relevant PAC information 
into the existing national registers $\left(\mathrm{MTUHA}^{9}\right)$, to avoid having parallel record keeping at facilities.

- FP counselling and methods: The majority of facilities have recorded impressive performances in terms of providing clients with FP counselling and methods. For those facilities where the proportions of clients not being counselled or leaving without a FP method is lower, the $\mathrm{MOH}$ needs to make site-specific assessments to address the reasons why this is happening. However, even at sites where clients reported being counselled on family planning, they were not given information on all contraceptives or common sideeffects. The $\mathrm{MOH}$ may consider developing job-aids to complement the PAC training material and additional training interventions, especially in family planning counselling.

- Provision of other RH services: Interviews with clients and service records indicate that the majority are not getting any counselling or information on STIs and HIV. Given that Geita District appears to have high rates of STIs ${ }^{10}$, the MOH needs to address this shortcoming by ensuring that routine post-procedure counselling includes STI/HIV counselling, and if necessary screening, perhaps through giving providers a job aid to remind them of the key elements they should cover in counselling.

- Community sensitisation/outreach: Despite being intended as a key component of this PAC intervention, apart from health talks given at the facilities and occasionally at village meetings, no systematic efforts have been made in community outreach. With the current shortage of staff in some health facilities, it is recommended that the MOH consider strengthening this component by involving community health workers and community liaison officers and providing IEC materials for distribution in the community.

In conclusion, this project has demonstrated that it is feasible to provide PAC services at dispensaries and health centres, and that this increases the proportion of women accessing services. Although the numbers of clients served at some of the facilities are not very high, the comparative benefit of having women access the service nearby, and thus averting negative consequences of the abortion is significant. The weaknesses identified in this study can easily be addressed through a committed effort on the part of ACQUIRE and the $\mathrm{MOH}$, especially during replication to new sites. This project offers a good example that can be borrowed by other countries in the region wishing to expand their PAC services to give access to more women.

9 MTUHA is an acronym for the national health management information registers (Mfumo wa Taarifa za Uendeshaji wa Huduma za Afya)

10 For example, records at the district hospital in 2004 showed that $6.4 \%$ of 1,093 ANC clients tested positive for syphilis. 


\section{References}

World Health Organization. 2004. "Unsafe Abortion: Global and regional estimates of incidence of unsafe abortion and associated mortality in 2002" $4^{\text {th }}$ edition, Geneva: World Health Organization.

Republic of Tanzania. 2004. "Geita District Health Budgets for Hospitals and Rural Health Facilities" Dar es Salaam: Ministry of Health.

Republic of Tanzania. 2002a. "Post Abortion Care Clinical Skills Curriculum, Volume 1: Trainer's Guide" Dar es Salaam: Ministry of Health.

Republic of Tanzania. 2002b. "Post Abortion Care Clinical Skills Curriculum, Volume 2: Trainer's Handbook" Dar es Salaam: Ministry of Health.

PRIME II, 2001 Reports

USAID. 2004. Post Abortion Care Strategy. Washington, D.C: USAID. 


\section{Annex: Summary of Resource requirements, Data Sources, Measurement and Collection Methods}

\begin{tabular}{|c|c|c|c|c|}
\hline Resources & Measurement & Data collection methods & Unit of Valuation & $\begin{array}{l}\text { Valuation data } \\
\text { Sources }\end{array}$ \\
\hline Labour time* & $\begin{array}{l}\text { Amount of time } \\
\text { service providers } \\
\text { spend managing } \\
\text { PAC clients }\end{array}$ & $\begin{array}{l}\text { Interviews with PAC } \\
\text { providers to establish the } \\
\text { amount of time they } \\
\text { spend managing clients }\end{array}$ & $\begin{array}{l}\text { Add salary and } \\
\text { other staff benefits }\end{array}$ & $\begin{array}{l}\text { Review of payroll } \\
\text { records }\end{array}$ \\
\hline $\begin{array}{l}\text { Drugs, FP } \\
\text { commodities, } \\
\text { IEC materials } \\
\text { and other } \\
\text { supplies }\end{array}$ & $\begin{array}{l}\text { Quantity used by } \\
\text { clients in the MVA } \\
\text { room }\end{array}$ & $\begin{array}{l}\text { Interviews with service } \\
\text { providers and record } \\
\text { review }\end{array}$ & $\begin{array}{l}\text { Market or } \\
\text { Government } \\
\text { supplied prices }\end{array}$ & $\begin{array}{l}\text { Review of } \\
\text { administrative } \\
\text { records kept by } \\
\text { stores and } \\
\text { medical supplies } \\
\text { unit }\end{array}$ \\
\hline $\begin{array}{l}\text { Equipment } \\
\text { (includes MVA } \\
\text { kits and space } \\
\text { refurbishment) }\end{array}$ & $\begin{array}{l}\text { Physical inventory } \\
\text { of space where } \\
\text { MVA procedures } \\
\text { performed }\end{array}$ & $\begin{array}{l}\text { Interviews with providers } \\
\text { and records review }\end{array}$ & $\begin{array}{l}\text { Expenditure per } \\
\text { year }\end{array}$ & $\begin{array}{l}\text { Review of } \\
\text { administrative } \\
\text { records kept by } \\
\text { stores and } \\
\text { medical supplies } \\
\text { unit }\end{array}$ \\
\hline $\begin{array}{l}\text { Transport, } \\
\text { administrative } \\
\text { costs and } \\
\text { Support } \\
\text { Infrastructure }\end{array}$ & $\begin{array}{l}\text { Budgeted } \\
\text { amounts for each } \\
\text { item }\end{array}$ & $\begin{array}{l}\text { Desk review of } \\
\text { administrative records }\end{array}$ & $\begin{array}{l}\text { Expenditure per } \\
\text { year. Allocated to } \\
\text { PAC services on } \\
\text { the basis of } \\
\text { workload }\end{array}$ & $\begin{array}{l}\text { Financial records } \\
\text { and budgets for } \\
2004\end{array}$ \\
\hline
\end{tabular}

Key informant interviews with service providers: Service providers were interviewed to identify resources used to provide PAC services. The out-come of the interviews were a consolidated checklist of resource inputs/requirements.

* Estimating direct labour time presented some challenges due to low utilization of PAC services in the facilities. On average health centres are seeing about 7 clients per month and the hospital 29. During the time of the study there were no single encounters with PAC clients and therefore we changed the approach earlier adopted to estimate both direct and indirect labor costs. In view of this limitations, frontline PAC providers were asked to estimate time they spend managing clients. This included conducting the MVA, drug administration and prescription, FP counselling and issuing commodities.

Review of administrative data- A checklist was used to review financial records such as staff payrolls and budgets. Payrolls were used to compute labour costs for PAC service providers while budgets provided information on program support costs (indirect) such as administration transport, utilities, maintenance and repairs). The budget information for the various facilities surveyed was obtained from the district hospital. Such information could not be obtained from health centres. Additional information gathered from facilities include utilization statistics (number of patients receiving PAC services, FP commodities issued, number of patients counseled, bed days, number of admissions, referrals and General outpatients visits. The information was used to allocate program support costs to PAC services/MVA room. 